\title{
Chemical Extraction Process for Producing High Purity Nanosilica from Iraqi Rice Husk
}

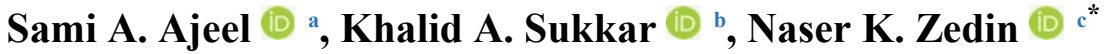 \\ ${ }^{a}$ Department of Production Eng. \& Metallurgy, University of Technology, Baghdad, Iraq. \\ 70003@uotechnology.edu.iq. \\ ${ }^{\mathrm{b}}$ Department of Chemical Eng., University of Technology, Baghdad, Iraq.150001@uotechnology.edu.iq. \\ ${ }^{\mathrm{c}}$ Department of Production Eng. \& Metallurgy, University of Technology, Baghdad, Iraq. \\ 70113@uotechnology.edu.iq. \\ *Corresponding author.
}

Submitted: 28/04/2020

Accepted: 17/06/2020

Published: $25 / 01 / 2021$

K E Y W O R D S

Nanosilica $\left(\mathrm{SiO}_{2}\right)$, Rice

Husk Ash (RHA),

Precipitation method,

Leaching acids process.

\begin{abstract}
A B S T R A C T
Rice husk is considered a main agricultural waste in Iraq. High purity $\mathrm{SiO}_{2} \mathrm{NPs}$ were produced from rice husk by enhanced precipitation and developed leaching processes for the preparation of silica from RH. In this study, pre-treatment for rice husk was with $3 \mathrm{~N} \mathrm{HCl}$, and calcination at $700^{\circ} \mathrm{C}$ was achieved, then followed with a leaching process with (1.5, 2, $2.5,3) \mathrm{N} \mathrm{NaOH}$ concentrations. The characterizations of the prepared $\mathrm{SiO}_{2} \mathrm{NPs}$ were studied by X-ray fluorescence (XRF), X-ray diffraction $(X R D)$, and atomic force microscopy (AFM). The results show that the prepared $\mathrm{SiO}_{2} \mathrm{NPs}$ have an amorphous structure with a high purity of 99.75\%. The results of the X-Ray confirm the amorphous nature of the extracted $\mathrm{SiO}_{2} \mathrm{NPs}$. Also, the AFM results indicated that the average diameter of the $\mathrm{SiO}_{2} \mathrm{NPS}$ was $85 \mathrm{~nm}$. It was noted that the leaching processes and pretreatment methods determine the structure, particle size, and quality of the synthesized $\mathrm{SiO}_{2} \mathrm{NPS}$.
\end{abstract}

How to cite this article: S. A. Ajeela, K. A. Sukkarb, and N. K. Zedin, "Chemical Extraction Process for Producing High Purity

Nanosilica from Iraqi Rice Husk" Engineering and Technology Journal, Vol. 39, Part A, No. 01, pp. 56-63, 2021.

DOI: https://doi.org/10.30684/etj.v39i1A.1696

This is an open access article under the CC BY 4.0 license http://creativecommons.org/licenses/by/4.0

\section{INTRODUCTION}

High purity nanosilica has unique properties that make it widely used in many applications as high capacity anodes, the conversion of solar energy, biomedical applications, and photovoltaic, electric, electronic devices [1-3]. The structure of the available silica in the earth's crust is either amorphous or crystalline. In the whole world, Rice is considered a basic source of food. Rice husk is generated during the rice milling process as a by-product [3]. The major inorganic component of the rice Husk is silica [4]. Per year, the world harvest of rice is evaluated at 500 million tons. The husk is 
considered as $20 \%$ of the grain, through the combustion of the husk, the ash is produced with a rate of $20 \%$ from the husk, and the obtained ash is estimated at 20 million tons. Usually, both rice husk and rice husk ash remain as industrial waste without use. So, many applications in industrial for rice husk ash has been researched. Also, using cheap resource materials like rice husk to produce important material as nano-silica produced a huge economic benefit due to reduce the cost and utilize of waste. The preparation process, properties, and applications of RHA are studied by extensive researches during the last three decades, also, this subject was studied with many pieces of research [5]. The nature of silica products (crystallinity and microstructure) is highly related to their application because the low reactivity of crystalline silica is limited to its direct applications [6]. The extracted silica from RHA is generally in an amorphous form with good properties. So, the amorphous silica can be obtained from RHA by using thermochemical processes. Comparing with crystalline silica, amorphous silica has interesting properties. In many chemical applications as absorbents, catalysts, and thermal insulators, amorphous silica has a high interest because of its proprieties like small particle size with high specific surface area [7-9]. Various synthetic methods of extracting nano-silica from RHA were used like chemical precipitation, ion exchange, solvent extraction, and electrolysis deposition method. Y. Shen [10] produced nano-silica from RHA by chemical method. They found the preparation conditions, time, the temperature of combustion have controlled the nature of the produced nano-silica thus the amorphous silica was formed at 550-800 ${ }^{\circ} \mathrm{C}$ and crystalline silica forms at temperatures higher than this. Nittaya and thuadaij [11], prepared nano-silica by precipitation method and characterized by many analytical techniques. They found that the obtained product was amorphous nano-silica and the specific surface area was $656 \mathrm{~m}^{2} \mathrm{~g}^{-1}$. Carmona et al. [12], extracted amorphous and white silica with both micro and nanometric particles from rice husk using mild acid solutions. They conducted that the prepared nano-silica was prepared by a precipitation process which was extracted from Iraq agriculture sources. Then, it was noted that the purity of nano-silica is dependent on many factors such as type of raw material, precipitation temperature, pretreatment steps, and the final purification process. All these parameters determine the quality and quantitative of produced nano-silica. Therefore, the main objective of the present investigation is to produce high purity nanosilica from agricultural wastes of rice husk by developed chemical extraction techniques.

\section{THE EXPERIMENTAL WORK}

\section{The raw materials}

The obtained rice husk ( $\mathrm{RH})$ was from Al-Najaf province -Iraq. Table I shows the chemical composition of rice husk (RH), it was obtained by carrying out extracted in the laboratory. Other chemicals such as sodium hydroxide $(\mathrm{NaOH})$, hydraulic acid $(\mathrm{HCl})$, and sulfuric acid $\left(\mathrm{H}_{2} \mathrm{SO}_{4}\right)$ were imported from Fluka Co.

TABLE I: The chemical composition of raw rice husk.

\begin{tabular}{cc}
\hline \hline Main Constituent's & wt\% \\
\hline Hemi cellulose & 20.7 \\
\hline Cellulose & 34.4 \\
\hline Lignin & 19.2 \\
\hline Ash Silica & 18.5 \\
Metallic oxides & $7.2\left(\mathrm{MgO}, \mathrm{NaO}, \mathrm{CaO}, \mathrm{Al}_{2} \mathrm{O}_{3}, \mathrm{~K}_{2} \mathrm{O},\right)$ \\
\hline
\end{tabular}

\section{Pre-treatment for rice husk (RH)}

For removing the soluble particles and dust, the rice husk was washing repeatedly by using the distilled water then dried by air at room temperature for $24 \mathrm{hrs}$. The pretreatment process was carried out by soaking $30 \mathrm{~g}$ of the dried rice husk in one liter of $3 \mathrm{~N}$ of $\mathrm{HCl}$ solution at $80{ }^{\circ} \mathrm{C}$ for $4 \mathrm{hrs}$. The mixture was then subjected to refluxing in the same acid at room temperature for $12 \mathrm{hrs}$. RH was then washed with deionized water and filtered many times to make it acid-free then dried in an oven at about $110^{\circ} \mathrm{C}$ for $4 \mathrm{hrs}$, as shown in Figure 1-a, b, c. 


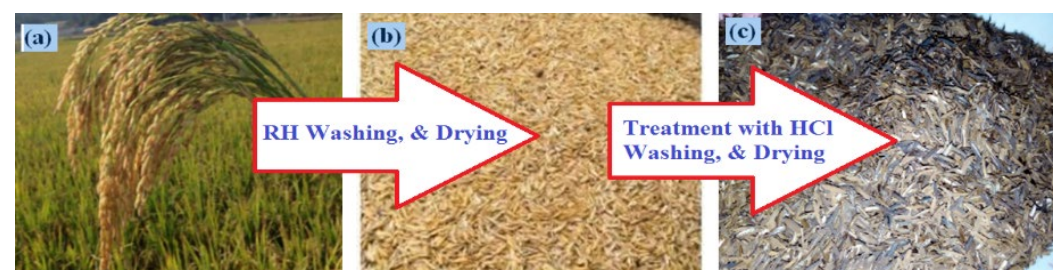

Figure 1: Agricultural Iraqi waste (Rice Husk) a) tuft of spikes b) RH without chemical treatment c) RH with chemical treatment.

\section{Calcination of rice husk (RH)}

The pre-treatment rice husk (RH), was burned at $700{ }^{\circ} \mathrm{C}$ in a muffle furnace for $4 \mathrm{hrs}$ at 10 ${ }^{\circ} \mathrm{C} / \mathrm{min}$, for removing the carbonaceous materials after that left to cool down. The obtained rice husk ash (RHA) becomes white color as shown in Figure 2.

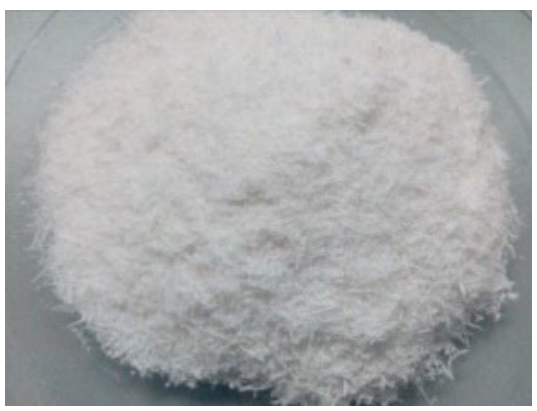

Figure 2: The rice husk ash (RHA) as agricultural Iraqi waste.

\section{Preparation for nanosilica}

Pure nano-silica was extracted by treating (20) g of RHA with $150 \mathrm{ml}$ of $(1.5,2,2.5,3) \mathrm{N} \mathrm{NaOH}$. The samples were stirred via magnetic stirrer at a constant rate and heated in a covered beaker of 250 $\mathrm{ml}$ at $70{ }^{\circ} \mathrm{C}$ for $3 \mathrm{hrs}$, as shown in Figure 3. By using filter paper Whatman (No.41 ashless), the solution of sodium silicate was filtered. So the obtained solution is $\left(\mathrm{Na}_{2} \mathrm{SiO}_{3}\right)$ as revealed in the below Equation.

$$
\mathrm{SiO}_{2}+2 \mathrm{NaOH} \rightarrow \mathrm{Na}_{2} \mathrm{SiO}_{3}+\mathrm{H}_{2} \mathrm{O}
$$

(ash) (sodium hydroxide) (sodium silicate) (water)

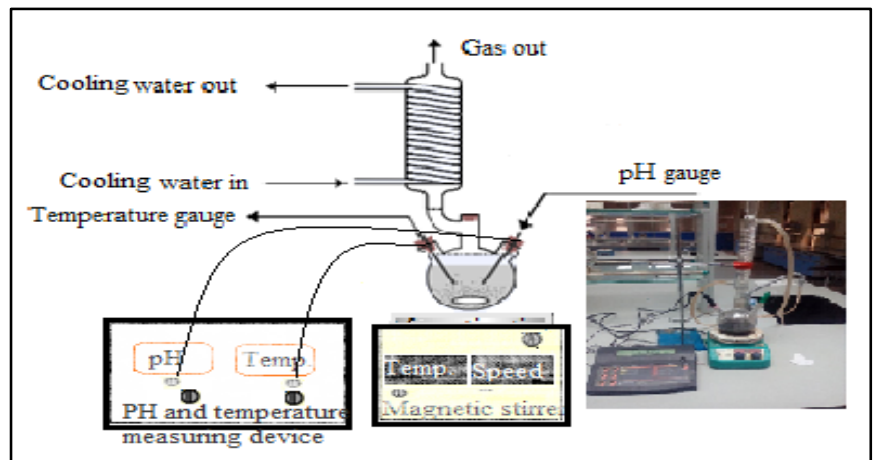

Figure 3: Silica nanoparticle production process, preparation pure nanosilica.

The residue solution was carefully washed with $(100 \mathrm{~mL})$ of boiling water. After that, the solution of sulphuric acid $5 \mathrm{~N} \mathrm{H}_{2} \mathrm{SO}_{4}$ was added to precipitate the solution of silicate as a white gelatinous solid $\left(\mathrm{SiO}_{2}\right)$ (by a gelation process).

$$
\mathrm{Na}_{2} \mathrm{SiO}_{3}+\mathrm{H}_{2} \mathrm{SO}_{4} \rightarrow \mathrm{SiO}_{2}+\mathrm{Na}_{2} \mathrm{SO}_{4}+\mathrm{H}_{2} \mathrm{O}
$$

(sodium silicate) (sulphuric acid) (High Purity silica) 
The residue soft gel was aged for $4 \mathrm{hrs,} \mathrm{after} \mathrm{aging,} \mathrm{the} \mathrm{slurry} \mathrm{was} \mathrm{washed} \mathrm{via} \mathrm{using} \mathrm{a} \mathrm{vacuum}$ filtration pump. $\mathrm{NH}_{4} \mathrm{OH}$ was added to make the $\mathrm{pH}=9$. Then, it left at room temperature for $4 \mathrm{hrs}$. By using filter paper Whatman (No.41 ashless), the solution was washed and filtered with $20 \mathrm{ml}$ warm deionized water many times to clear it of alkali and dry it at a temperature of $90{ }^{\circ} \mathrm{C}$ for $10 \mathrm{hrs}$ inside the oven. The obtained powder was refluxed with $6 \mathrm{~N} \mathrm{HCl}$ for $4 \mathrm{hrs}$ and washed with deionized water, after washing, $2.5 \mathrm{~N} \mathrm{NaOH}$ was added and stirred by magnetic stirrer and heated at $70{ }^{\circ} \mathrm{C}$ for 3 hrs inside $250 \mathrm{ml}$ covered beaker then $5 \mathrm{~N} \mathrm{H}_{2} \mathrm{SO}_{4}$ was added to obtain white nanoparticles with high purity of $\left(\mathrm{SiO}_{2}\right)$ after washing and filtering by Whatman (No.41 ashless). As shown in the flow chart in Figure 4, the precipitated nanosilica was washed repeatedly with warm deionized water until it becomes completely alkali-free then filtered and the remainder was collected and dried at $110{ }^{\circ} \mathrm{C}$ for $12 \mathrm{hrs}$ in the oven furnace. The final product is nanosilica by precipitation method.

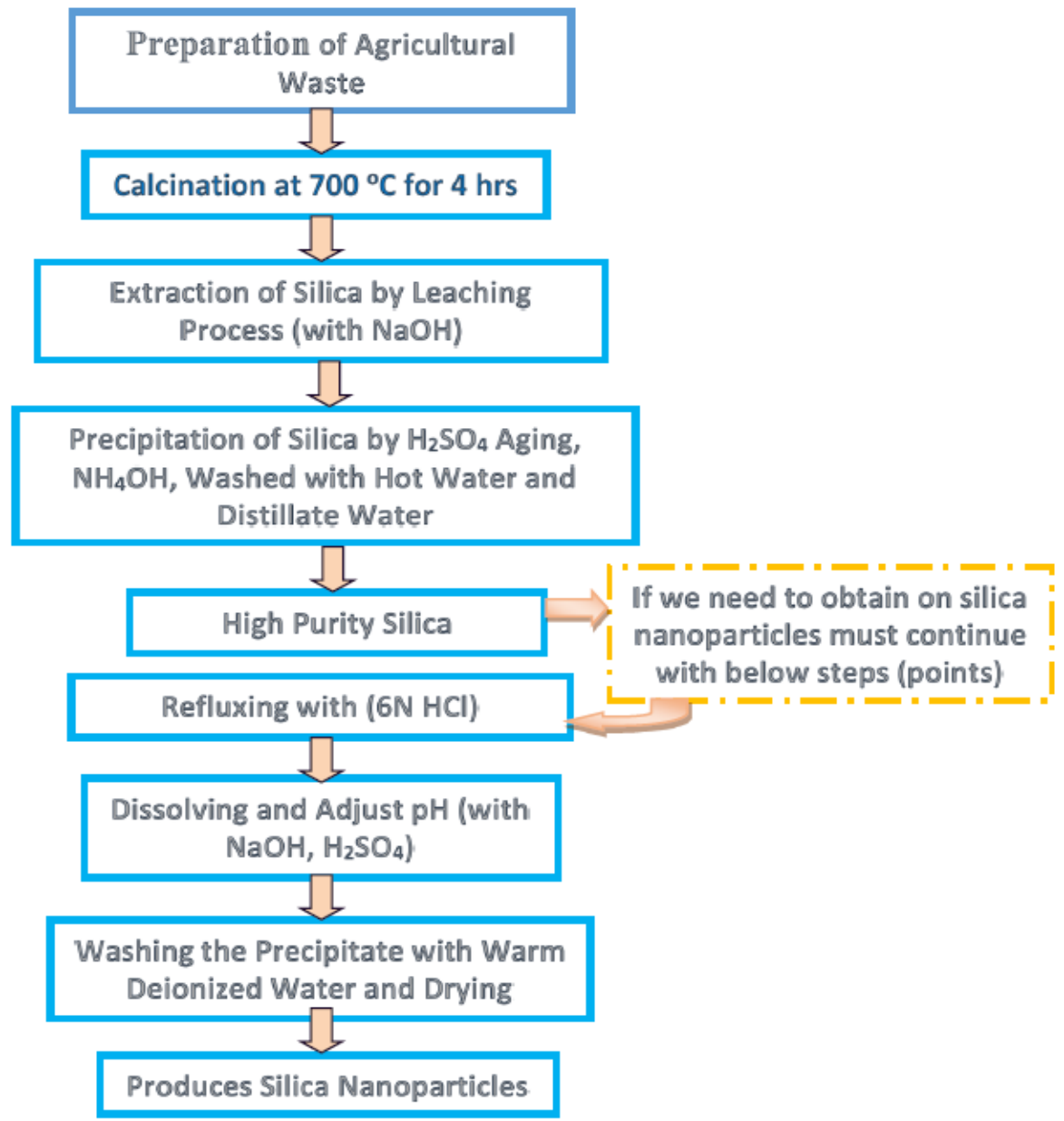

Figure 4: Flow chart for preparation of high purity silica and nanosilica by precipitation method.

\section{THE RESULTS WITH DISCUSSION}

\section{I. $X R F$ results}

Purity for the prepared silica from rice husk was measured by X-ray fluorescence (XRF). Table II illustrates the chemical analysis of prepared nano-silica which was prepared at $700{ }^{\circ} \mathrm{C}$, it is noteworthy that the choice of the temperature of the calcination at $700{ }^{\circ} \mathrm{C}$ was dependent on the previous studies of research $[8,11]$. Therefore, it concluded that calcination at a temperature above $700{ }^{\circ} \mathrm{C}$ gives crystal silica. On the other hand, the calcination at a temperature of less than $700{ }^{\circ} \mathrm{C}$ gives less purity for the produced silica. Accordingly, the choice calcination temperature at $700{ }^{\circ} \mathrm{C}$ to give pure amorphous silica. It was noted that the nano-silica purity reaches to $99.917 \mathrm{wt} \%$ from Iraq rice husk. To evaluate the effect of $\mathrm{NaOH}$ concentration on nano-silica powder, $\mathrm{XRF}$ analysis is used for quantitatively investigating the level of impurities in nano-silica $\left(\mathrm{SiO}_{2}\right)$ and evaluating the 
purification effect at $(1.5,2,2.5,3) \mathrm{N} \mathrm{NaOH}$ treatments. Table II shows XRF for nano-silica at the best extraction condition obtained in this study (with pre-treatment of $3 \mathrm{~N} \mathrm{HCl}$ and calcination temperature at $700 \mathrm{oC}$ for $4 \mathrm{hrs}$ ), it shows the ratio of nano-silica and the major inorganic oxides such as $\mathrm{CaO}, \mathrm{Fe}_{2} \mathrm{O}_{3}, \mathrm{~K} 2 \mathrm{O}, \mathrm{Cr}_{2} \mathrm{O}_{3}$, and $\mathrm{MnO}$ exist with the various amounts relying on the concentration of $\mathrm{NaOH}$. The purity of extracted nano-silica is affected by the presence of these oxides. The purity of nano-silica increases with increasing the concentration of $\mathrm{NaOH}$ from $98.4 \%$ to $99.9 \%$ respectively. This result is an agreement with researches [14-18].

TABLE II: XRF analysis of nanosilica composition at different concentrations of $\mathrm{NaOH}$.

\begin{tabular}{|c|c|c|c|c|}
\hline \multirow{2}{*}{$\begin{array}{c}\text { Components } \\
\%\end{array}$} & \multicolumn{4}{|c|}{ Treatment with $\mathrm{NaOH}$} \\
\hline & $1.5 \mathrm{~N}$ & $2 N$ & $2.5 \mathrm{~N}$ & $3 N$ \\
\hline $\mathrm{SiO}_{2}$ & 98.43 & 99.318 & 99.753 & 99.917 \\
\hline $\mathrm{K}_{2} \mathrm{O}$ & 0.004 & 0.001 & 0.003 & 0.003 \\
\hline $\mathrm{Fe}_{2} \mathrm{O}_{3}$ & 0.704 & 0.207 & 0.142 & 0.018 \\
\hline $\mathrm{CaO}$ & 0.093 & 0.048 & 0.002 & 0.013 \\
\hline $\mathrm{Cr}_{2} \mathrm{O}_{3}$ & 0.020 & 0.009 & 0.001 & - \\
\hline MnO & 0.062 & 0.008 & 0.001 & 0.003 \\
\hline $\mathbf{P}_{2} \mathbf{O}_{5}$ & 0.657 & 0.352 & 0.096 & 0.029 \\
\hline Others & 0.022 & 0.057 & 0.002 & 0.017 \\
\hline
\end{tabular}

The relationship between the degree of purity for extraction nanosilica and $\mathrm{NaOH}$ concentration is show in Figure 5. It indicates that within increase $\mathrm{NaOH}$ concentration, the purity increased.

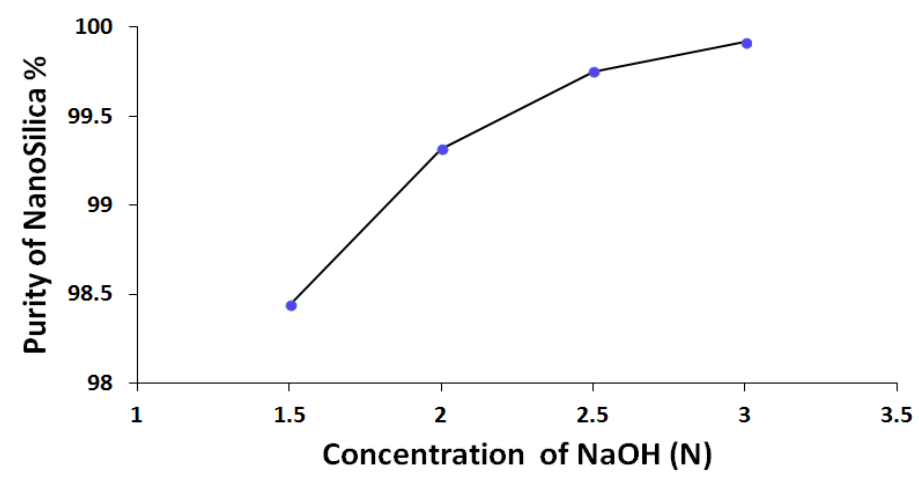

Figure 5: The relationship shows the effect of $\mathrm{NaOH}$ concentration on purity nanosilica.

\section{X-Ray Diffraction}

To confirm the crystalline and amorphous nature of the produced powders, an X-ray diffraction (XRD) test was achieved on the obtained silica at $(1.5,2,2.5$, and 3) $\mathrm{N} \mathrm{NaOH}$ concentrations. Figure 6 shows the XRD patterns of as-prepared nanosilica powder in the range of $2 \theta=0-60^{\circ}$. At $2 \theta=\sim 17$ - $29^{\circ}$, a broad peak was noticed corresponding to amorphous silica depending on JCPDS-card \# 96412-4080. The prepared nanosilica doesn't show any sharp peaks as a result of obtaining amorphous silica without crystalline structure. Figure 6 shows spectrums with high smoothness, the smoothness of the spectrum pointed out the high efficiency of impurities removal of acid leaching process from RHA. Also, the acid leaching is attributed to the amorphous nature of nanosilica. With acid leaching, however, the crystal form doesn't show up even at temperatures higher than $700{ }^{\circ} \mathrm{C}$ and then returns to remove some ions which were activated the crystallization of nanosilica. XRD analyses in Figure 6 reveal that changing the concentration of $\mathrm{NaOH}$ has affected the curves of nanosilica. From the figures it can be noted, the obtained curves were completely amorphous and the degree of smoothness of the curves was increased by raising the concentration of $\mathrm{NaOH}$ from $1.5 \mathrm{~N}$ to $3 \mathrm{~N}$. This result is in total agreement with the fact that $\mathrm{NaOH}$ solubilizes only amorphous silica. 


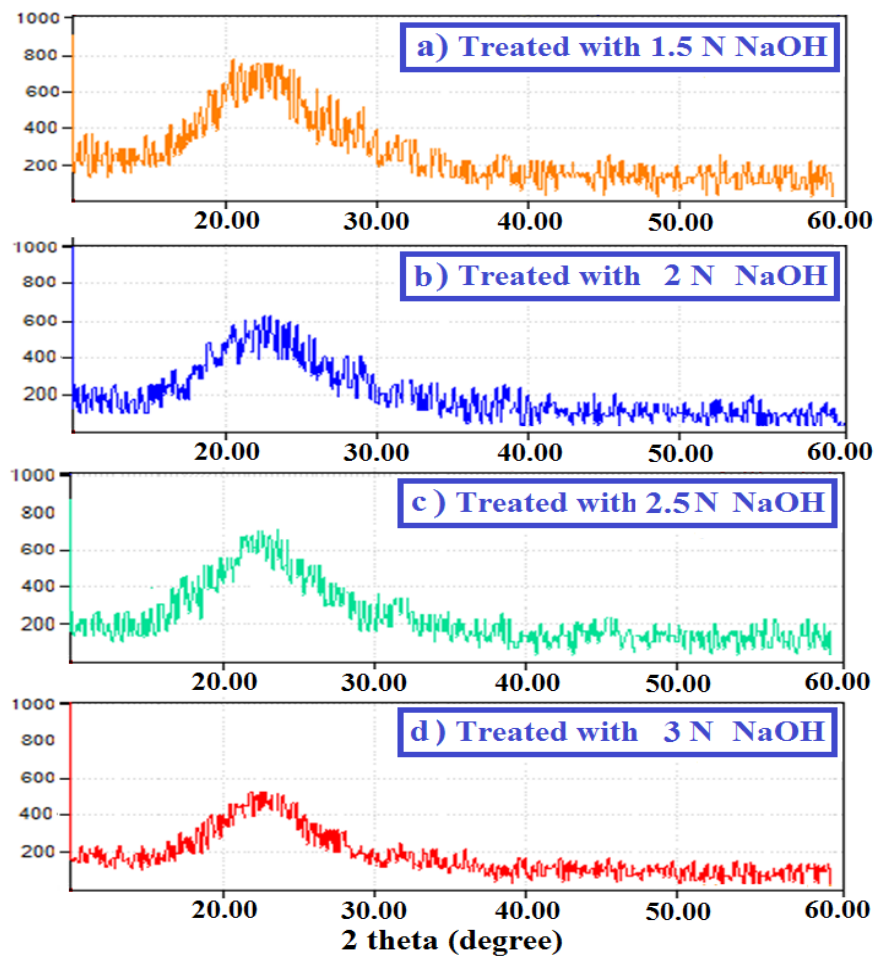

Figure 6: X-Ray diffraction XRD nanosilica at a) $1.5 \mathrm{NaOH}$, b) $2 \mathrm{NaOH}$, c) $2.5 \mathrm{NaOH}$, d) $3 \mathrm{NaOH}$.

\section{Atomic force microscopy (AFM) and Particle Size of Nanosilica}

The AFM analysis was applied to characterize the obtained silica nanoparticles' average diameter at each concentration of $\mathrm{NaOH}$ from 1.5 to $3 \mathrm{~N}$ with the scanned area $\left(2534^{*} 2534\right) \mathrm{nm}$ for the samples with high-resolution $(416 * 416)$ pixel as shown in Figure 7. The morphology and diameter of the extracted silica nanoparticles from agricultural Iraqi were affected by changing the concentration of $\mathrm{NaOH}$ from 1.5 to $3 \mathrm{~N}$ through extracted $\mathrm{SiO}_{2}$ nanoparticles. According to AFM analysis, the diameters of prepared silica nanoparticles $\left(\mathrm{SiO}_{2} \mathrm{NPs}\right)$ extracted at $1.5 \mathrm{~N} \mathrm{NaOH}$ were in the range of $(65-115 \mathrm{~nm})$ and the average diameter equal to $74.70 \mathrm{~nm}$ as shown in Figure 7 -a, that show threedimensional surface images. It is confirmed that nano-silica particles are spherical. Also, at $2 \mathrm{~N}$ concentration of $\mathrm{NaOH}$, the diameters of silica nanoparticles $\left(\mathrm{SiO}_{2} \mathrm{NPs}\right)$ were in the range of $(20-120$ $\mathrm{nm}$ ) and the average diameter of $78.25 \mathrm{~nm}$, the 3D surface image of $\mathrm{SiO}_{2} \mathrm{NPs}$ extracted at $2 \mathrm{~N} \mathrm{NaOH}$ shows particles have a spherical shape and bigger size than the particles obtained at $1.5 \mathrm{~N} \mathrm{NaOH}$, as shown in Figure 7-b. The AFM images of silica nanoparticles obtained at $2.5 \mathrm{~N} \mathrm{NaOH}$ display keeping the spherical shape of particles with the increase in the size of particles in which the range of particle diameters is $(75-100 \mathrm{~nm})$ and the average diameter is $79.76 \mathrm{~nm}$ as shown in Figure 7-c. The 3D surface image of silica nanoparticles prepared at $3 \mathrm{~N} \mathrm{NaOH}$ appears the surfaces of silica nanoparticles have the valleys and hills shape. Valley shapes are comparatively smooth, and the hill shapes have crystal-like structures. The diameters of prepared nano-silica are in the range of (70 165) $\mathrm{nm}$ and the average diameter equal to $88.93 \mathrm{~nm}$, as shown in Figure 7-d.

In general, All these results reveal that increasing the concentration of $\mathrm{NaOH}$ led to a rise in the size of the particles. On the other hand, the shape of particles can be changed from spherical which was obtained at $\mathrm{NaOH}$ concentration led from $1.5-2.5 \mathrm{~N}$ to crystal-like structures at $3 \mathrm{~N} \mathrm{NaOH}$ concentration. 


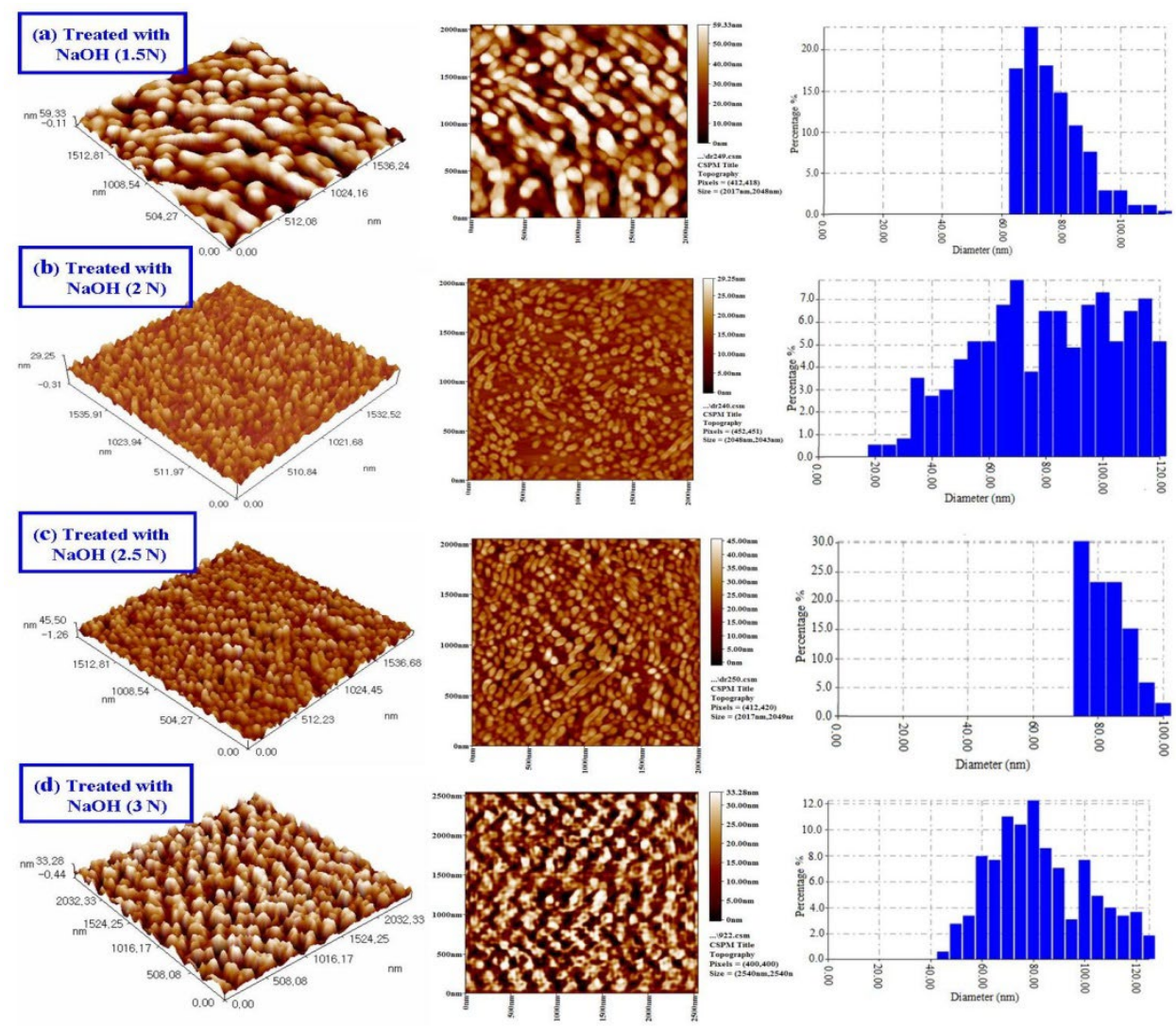

Figure 7: AFM photograph of 2D and 3D of prepared nanosilica at different $\mathrm{NaOH}$ concentrations: a) 1.5 , b) 2 , c) 2.5 , and d) $3 \mathrm{~N}$.

\section{Conclusions}

An amorphous $\mathrm{SiO}_{2} \mathrm{NPs}$ was successfully prepared from rice husk by chemically modified precipitation technique. The chemical treatment processes were the main affective parameters for producing high purity nano-silica $(99.917 \%)$. This study showed that with an increase in $\mathrm{NaOH}$ concentration from 1.5 to $3 \mathrm{~N}$, the purity of the extracted silica increased. Whereas, AFM results showed that the increases in $\mathrm{NaOH}$ concentration will increase the size of the silica particles. Also, with increasing the concentration of $\mathrm{NaOH}$ to higher than $2.5 \mathrm{~N}$, the particle size will be increased more than of nano-scale. This study showed that at $3 \mathrm{~N} \mathrm{NaOH}$ solution, amorphous silica nanoparticles with the highest degree of purity were extracted from RH. The main particle size of the prepared nano-silica was 40-89 $\mathrm{nm}$. From an engineering point of view, the modified production method is economic, flexible non-complicated, and produced high-quality amorphous nano-silica. Then, the process could be used for production on an industrial scale.

\section{References}

[1] R. R. Swetha, Studies of nitric acid attack on rice husk ash concrete, Int. J. Civ. Eng. Technol., 8 (2017) 927-934.

[2] M. Al Mubarok, L. P. Setiawan, M. Utami, W. Trisunaryanti, Study of acid leaching in the preparation of silicon from lapindo mud, Int. J. Acad. Sci. Res., 2 (2014) 31-36.

[3] P. P. Nayak, S. Nandi, A. K. Datta, Comparative assessment of chemical treatments on extraction potential of commercial grade silica from rice husk, Eng. Rep., 1 (2019) 1-13. https://doi.org/10.1002/eng2.12035

[4] V. B. Carmona, R. M. Oliveira, W. T. L. Silva, L. H. C. Mattoso, J. M. Marconcini, Nanosilica from rice husk: extraction and characterization, Ind. Crops Prod., 43 (2013) 291- 296. https://doi.org/10.1016/j.indcrop.2012.06.050 
[5] N. Soltani, A. Bahrami, M.I. Pech-Canul, L.A. González, Review on the physicochemical treatments of rice husk for production of advanced materials, Chem. Eng. J., 264 (2015) 899-935. https://doi.org/10.1016/j.cej.2014.11.056

[6] D. Barana, A. Salanti, M. Orlandi, D. S. Alia, L. Zoia, Biorefinery process for the simultaneous recovery of lignin,hemicelluloses, cellulose nanocrystals and silica from rice husk and arundo donax, Ind. Crops Prod., 86 (2016) 31-39. https://doi.org/10.1016/j.indcrop.2016.03.029

[7] D. S. Junga, M. H. Ryoua, Y. J. Sung, S. B. Park, J. W. Choi, Recycling rice husks for high-capacity lithium battery anodes, PNAS, 110 (2013) 12229-12234. https://doi.org/10.1073/pnas.1305025110

[8] N. K. Zedin, S. A. Ajeel, K. A. Sukkar, Nanosilicon powder extraction as a sustainable source (from Iraqi rice husks) by hydrothermal Process, AIP Conference Proceedings, 2213, 2020, 020155. https://doi.org/10.1063/5.0000147

[9] B. Usman, I.A. Rufai, Extraction and characterization of solar-grade biosilica from rice husk, International Conference on Agriculture and Food Engineering for Life, Cafei, 2012, 225-231.

[10] Y. Shena, Rice husk silica derived nanomaterials for sustainable applications, Renew. Sustain. Energy Rev., 80 (2017) 453-466. https://doi.org/10.1016/j.rser.2017.05.115

[11] N. Thuadaij, A. Nuntiya, Synthesis and characterization of nanosilica from rice husk ash prepared by precipitation method, Special Issue on Nanotechnology, 7 (2008) 59-65.

[12] V. H. Le, C. N. H. Thuc , H. H. Thuc, Synthesis of silica nanoparticles from Vietnamese rice husk by solgel method, Nanoscale Research Letters, 8 (2013)2-10. https://doi.org/10.1186/1556-276x-8-58

[13] L. Zong, B. Zhu, Z. Lu, Y. Tan, Y. Jin, N. Liu, Y. Hua, Sh. Gu, J. Zhu, Y. Cui, Nanopurification of silicon from $84 \%$ to $99.999 \%$ purity with a simple and scalable process, PNAS, 112 (2015) 13473-13477. https://doi.org/10.1073/pnas.1513012112

[14] W.A.P.J. Premaratne, W.M.G.I. Priyadarshana, S.H.P. Gunawardena , A.A.P. De Alwis, Synthesis of nanosilica from paddy husk ash and their surface functionalization, J. Sci. Univ. Kelaniya, 8 (2013) 33-48.

[15] A. A. Moosa, B. F. Saddam, Synthesis and characterization of nanosilica from rice husk with applications to polymer composites, Am. J. Mater. Sci., 7 (2017) 223-231.

[16] R. Yuvakkumar, V. Elango, V. Rajendran, N. Kannan, High-purity nano silica powder from rice husk using a simple chemical method, J. Exp. Nanosci., 9 (2014) 272-281. https://doi.org/10.1080/17458080.2012.656709

[17] R. A. Bakar, R. Yahya, S. N. Gan, Production of high purity amorphous silica from rice husk, Procedia Chem., 19 (2016) 189-195. https://doi.org/10.1016/j.proche.2016.03.092

[18] E. Rafiee, S. Shahebrahimi1, M. Feyzi, M. Shaterzadeh, Optimization of synthesis and characterization of nanosilica produced from rice husk (a common waste material), Int. Nano Lett., 2 (2012) 2-8. https://doi.org/10.1186/2228-5326-2-29 